\section{HISTORIA DE UN FRACASO: EL “HIMNO NACIONAL” EN LA ESPAÑA DEL SIGLO XIX}

\author{
María Nagore Ferrer \\ Universidad Complutense de Madrid \\ mnagoref@ghis.ucm.es
}

\begin{abstract}
Music as a vehicle susceptible of moving and transmitting ideological contents has always played a prominent role in social struggle. Particularly relevant in this regard is the role of music in the patriotic or political mobilization of societies and cultures, which is a form of mass mobilization. "National anthems" achieved great importance in Europe and America, coinciding with the processes of revolution and independence, and with the increasing national consciousness in many territories during the nineteenth century. In Spain, however, several attempts to establish a national anthem failed. The "royal march" worked de facto as national march, but it did not have enough social support or the symbolic dimension to constitute a "national anthem". In the 1830-40's many voices claimed that the Himno de Riego was declared national anthem. In the 60's, coinciding with the African War, composers as Chueca or Gabalda wrote national hymns as well; even someone suggested that a cantiga of Alfonso X el Sabio became a hymn. In 1896 there was also an attempt to transform the march of the Zarzuela Cádiz, of Chueca, in a national hymn. And still in the early twentieth century many voices insisted on the need for Spain to have a national anthem. During those years on fashion hymns were very important, and many of them, from different countries, were published in arrangement for piano. This article tries to explore this process, analyzing the causes of the successive failures from the social, political and musical points of view.
\end{abstract}

KEY WORDS: National anthems; Spanish National Anthem; Royal March; National March; Himno de Riego.

No es nuestro objetivo en este trabajo llevar a cabo un análisis del origen y la historia del himno nacional español, tema que ya ha sido objeto de varios estudios ${ }^{1}$, sino tratar de mostrar los vínculos entre música e identidad nacional en España a través de un símbolo de tanta fuerza como el "himno nacional", necesidad creciente en el siglo XIX en las naciones europeas y americanas.

Siendo el himno un símbolo que pone en juego los sentimientos subjetivos y la emoción individual y colectiva,

\section{THE STORY OF A FAILURE: THE "NATIONAL ANTHEM" IN NINETEENTH CENTURY SPAIN}

RESUMEN: La música, como vehículo susceptible de conmover y transmitir una carga ideológica, siempre ha desempeñado un destacado papel en las movilizaciones sociales. Especialmente relevante, en este sentido, es el papel de la música en la movilización patriótica o política de las sociedades y las culturas, que es una forma de movilización de masas. En el siglo XIX toman mucha fuerza en Europa y América los "himnos nacionales", coincidiendo con los procesos revolucionarios e independentistas y con la creciente conciencia nacional en los distintos territorios. En España, sin embargo, los diversos intentos de establecer un himno nacional fracasaron. La "marcha real" funcionó de facto como marcha nacional, pero no tuvo el respaldo social ni la carga simbólica suficiente como para constituir un "himno nacional". En los años 1830-40 muchas voces pidieron que el Himno de Riego fuera proclamado himno nacional; en los años 60, coincidiendo con la guerra de África, compositores como Gabaldá o Chueca escribieron himnos nacionales, incluso se propuso que una cantiga de Alfonso $X$ el Sabio se convirtiera en himno. En 1896 se intentó convertir en himno nacional la marcha de la zarzuela Cádiz, de Chueca. Y todavía en los primeros años del siglo $X X$ hubo muchas voces que insistieron en la necesidad de que España tuviera un himno nacional: en esos años tuvo mucha fuerza la "moda" de los himnos, publicándose en arreglos para piano himnos nacionales de distintos paises. En este artículo se explicará este proceso, analizando las causas de estos fracasos tanto desde el punto de vista político-social como musical.

PALABRAS CLAVE: Himnos nacionales, Himno nacional español, Marcha real, Marcha nacional, Himno de Riego.

contribuye de una manera decisiva a la construcción -0 no- de una identidad nacional. Cuando leemos en las páginas de un periódico de 1836, en plena guerra carlista, que una orden que prohibía el toque de himnos había contribuido a desalentar al ejército y había tenido funestas consecuencias en la marcha de la guerra, o en un periódico socialista de 1905 que "el Himno de Riego y La Marsellesa han despertado más inteligencias y hecho palpitar más corazones que el sinfín de discursos políticos pronunciados en este país en todas las agitaciones sociales del siglo 
anterior"2, podríamos pensar que los autores de estos textos atribuyen a la música una influencia exagerada. Sin embargo, la historia nos ofrece innumerables ejemplos del poder que ejerce la música asociada a determinadas ideas y circunstancias: enciende los ánimos, infunde valor, provoca movilizaciones patrióticas o políticas, inculca ideas o consignas, etc.

Como afirma Esteban Buch, la grandilocuencia que impregna los himnos nacionales "sirve para expresar a veces cierta oposición e incluso para propagar la revuelta o la revolución, pero también puede contribuir a garantizar la legitimidad del poder constituido y la adhesión al orden establecido bajo la forma de una música de Estado, es decir, una música reconocida como gesto o discurso político, cuya producción o interpretación tienen lugar por acción del Estado"3. En el caso español, las dificultades para la implantación de un auténtico himno nacional en la mayor parte del siglo XIX pueden verse como un reflejo de la debilidad del estado ${ }^{4}$, pero seguramente influyeron también en la debilidad de una conciencia de identidad nacional. Todavía en 1901, a la vuelta de un siglo convulso, se pedía desde las páginas de un diario nacional:

\begin{abstract}
Necesitamos un himno. No es nuestra necesidad más apremiante, pero es sin duda una necesidad. Hace falta una armonía que exalte en los corazones el patriotismo, que aliente al ciudadano en la labor y al soldado en el combate, cuyas estrofas resuenen en el taller, en la escuela, en el cuartel, en la plaza pública, que sea para los propios entusiasmos y en los extraños homenajes, que sirva para el mutuo cambio de agasajos en las solemnidades internacionales. Un himno es tan necesario para los pueblos como los colores de la bandera o los emblemas del escudo. España está afónica. Necesitamos un himno nacional que venga a ser como la voz misma de la patria ${ }^{5}$.
\end{abstract}

\section{El Himno de Riego, primer "himno nacional"}

Como es bien conocido, el origen del actual himno nacional de España es la Marcha granadera, uno de los toques incluidos en las Ordenanzas Generales promulgadas por el rey Carlos III en 1768. Eran dieciséis los "Toques que han de observar los tambores y pífanos" establecidos en las ordenanzas, entre ellos la Marcha y la Marcha granadera.
Estos toques se detallaron en 1769 en el libro Toques de guerra que deberán observar uniformemente los pifanos, clarinetes y tambores de S.M. concertados por Dn. Manuel de Espinosa, músico de la Capilla Real, que incluye dos marchas: la Marcha de Fusileros y la Marcha de Granaderos. Las funciones de estas marchas eran las siguientes: rendir honores militares al Santísimo Sacramento, al Rey y a otras personas reales, a los capitanes generales del ejército o de las provincias en ausencia del Rey y al General del ejército en campaña (función para la que se designó poco tiempo después a la Marcha granadera); acompañar la marcha de la tropa con la formalidad correspondiente; y saludar a las banderas. Estas ordenanzas siguieron vigentes en los reinados de Fernando VII y de Isabel II, por lo tanto la Marcha Granadera continuó ejerciendo la función de marcha de honor. Desde 1840 aproximadamente se empezó a utilizar la expresión "Marcha real" para referirse a ella, denominación que se generalizó a partir del ascenso al trono de Isabel II, tras el período de la Regencia, en 1843.

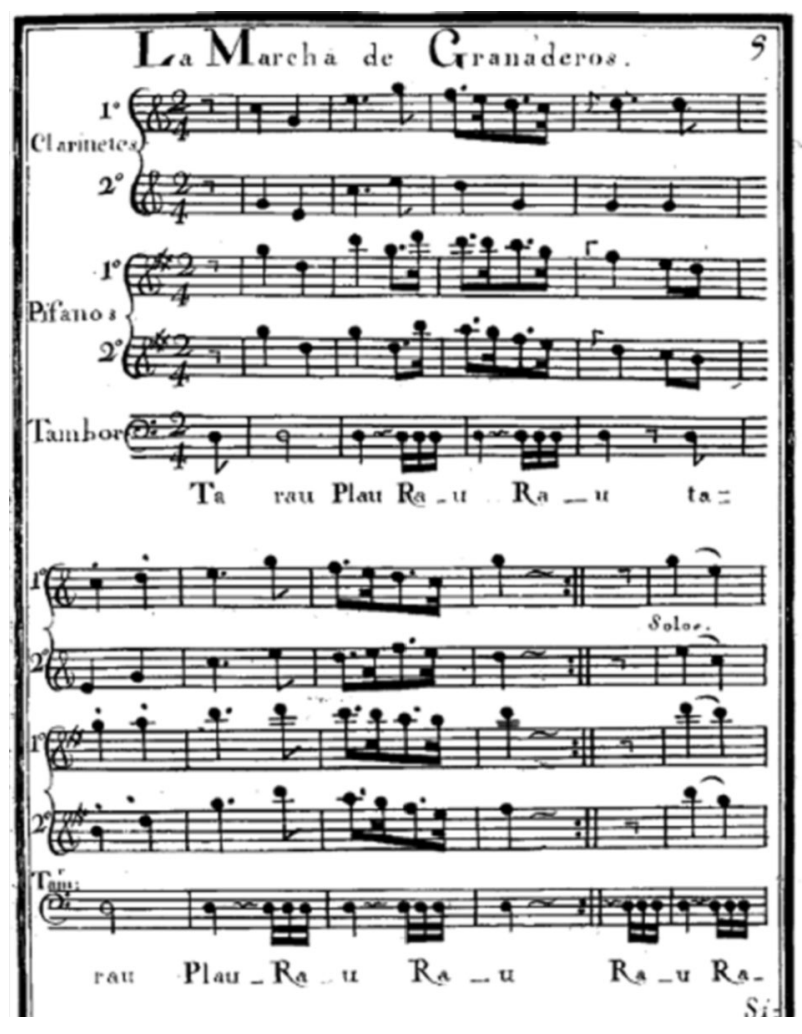

Inicio de la Marcha de Granaderos tal como aparece en el libro Toques de guerra..., Madrid, 1769, p. 9. 
Desde nuestro punto de vista, es problemático considerar a esta marcha "himno nacional", ni siquiera oficiosamente, como afirman algunos autores ${ }^{6}$, en la primera mitad del siglo XIX. Y no porque no tenga letra, como se ha dicho en muchas ocasiones. Aunque en puridad el término "himno" implique un texto7, empleamos la expresión "himno nacional" en el sentido de la última acepción de la palabra "himno" en el Diccionario de la Lengua Española: "Composición musical emblemática de una colectividad [en este caso una nación], que la identifica y que une entre sí a quienes la interpretan [y/o la escuchan, deberiamos añadir]". Gran parte de los himnos nacionales que se instauraron en los distintos paises del globo en los siglos XIX y XX fueron en su origen canciones patrióticas con las que el pueblo se identificaba. Es el caso de dos de los más antiguos, adoptados en el siglo XVIII, el God save the King/Queen británico y La Marsellesa francesa. No fue ese el caso de la Marcha granadera, como veremos.

Es interesante constatar que la expresión "himno nacional", muy poco utilizada en España en el siglo XIX, aparece por primera vez en 1820 y aplicada al Himno de Riego ${ }^{8}$. Durante los años de la Guerra de la Independencia habian proliferado los himnos patrióticos, que florecen nuevamente ese año tras el éxito del pronunciamiento del general Riego en Las Cabezas de San Juan y la reinstauración de la Constitución de 1812. Entre estos himnos o cantos patrióticos se impuso enseguida el dedicado al propio artífice del cambio, el "himno del inmortal Riego", cantado en calles, plazas y teatros acompañado por vivas a la Nación, a la Constitución y al Rey Constitucional:

Concluida la votación, y cantado en la iglesia de Santa María el Te Deum de costumbre, un numeroso concurso de ciudadanos acompañó al Señor jefe político y Señores electores hasta la casa del primero, dirigiéndose por la plaza de la Constitución, calles de Atocha y Carretas, Puerta del Sol, calles de la Montera y Hortaleza hasta la de la Reyna. La música del regimiento de Fernando VII repitió por toda la carrera el armonioso y patriótico himno de Riego, habiéndose repetido con el mayor entusiasmo los vivas a la Nación, al Rey Constitucional, a los electores, al pueblo de Madrid, al jefe político, etc. ${ }^{9}$.

La efervescencia y el entusiasmo popular que acompañan a estos acontecimientos se desbordan por medio de las inflamadas estrofas guerreras escritas por Evaristo San Miguel: "Soldados, la patria / nos Ilama a la lid, / juremos por ella / vencer o morir", que rememoran las heroicas hazañas bélicas del pueblo contra el invasor francés $y$, por extensión, contra los enemigos de la libertad: "Volemos, que el libre / por siempre ha sabido / al siervo rendido / la frente humillar". Las dos ideas principales del texto, Patria y libertad, se asocian en las manifestaciones populares y festivas con la de Constitución, como refleja la cita anterior y como se pone de manifiesto en las funciones organizadas en los teatros de Madrid en abril y mayo de 1820:

Mañana en este teatro [del Príncipe] se ejecutará la comedia original en 2 actos del célebre Martínez de la Rosa, titulada iLo que puede un empleo! y el fin de fiesta la Palabra Constitución, adornada de bailes, canciones patrióticas, y del Himno del inmortal D. Rafael del Riego, música nueva, compuesta por D. Esteban Moreno, maestro de este arte en el referido teatro, y que cantarán las señoras (sic) Benita Moreno, Dionisio López y demás individuos de que se compone la compañia.

En el de la Cruz, a las $7^{1 / 2}$ de la noche, se ejecutará la comedia en 5 actos titulada la Fuerza de las Leyes, cuyo argumento manifiesta la severidad con que deben sostenerse por los que obtienen el grave encargo de aplicarlas; concluida se cantará el Himno Nacional con coplas nuevas; se bailarán manchegas a cuatro, y se dará fin con el gracioso sainete el Alcalde discreto ${ }^{10}$.

Llama la atención, en esta cita, la alusión al himno de Riego con la expresión "el Himno Nacional", fórmula que, aunque minoritaria, expresa bien el significado que adquirió este himno en la conciencia colectiva de los españoles. Apoya esta hipótesis la carta publicada por el periódico El Constitucional el 25 de abril de 1820, referida precisamente a la interpretación del himno de Riego en las funciones celebradas en el Teatro del Príncipe. Su autor describe cómo al oír el himno "nos inflamábamos de un ardor verdaderamente patriótico" y pide a los españoles que hagan lo mismo que los ingleses, que "cuando cantan su God save the King se ponen en pie, se quitan el sombrero, y guardan el más profundo y respetuoso silencio", lo mismo que los franceses y portugueses" ${ }^{11}$. Esta petición manifiesta que este himno era asumido en ese momento como himno nacional.

Álvarez Junco afirma que fue en el Cádiz de las Cortes donde los términos heredados de reino y monarquía fueron sustituidos por nación, patria y pueblo, lo que suponía todo un cambio de ambiente ${ }^{12}$. Es cierto que se trataba de un 
concepto de nación aún muy emocional, era una nación del pueblo y no del Estado. Pero en el breve período del Trienio Constitucional se iniciaron una serie de medidas y reformas tendentes a la consecución de una "nación institucional" a través de los cauces liberales, y una de estas medidas fue declarar el himno de Riego marcha nacional de ordenanza. El Decreto XIV de 7 de abril de 1822, expedido por las Cortes, dice así:

Las Cortes, usando de la facultad que se les concede por la Constitución, han decretado lo siguiente:

Art. 1. Se tendrá por marcha nacional de ordenanza la música militar del himno de Riego que entonaba la columna volante del ejército de $\mathrm{S}$. Fernando mandada por este caudillo.

2. Este decreto se comunicará en la orden de todos los cuerpos del Ejército, Armada y Milicia nacional al frente de banderas.

3. El Gobierno cuidará se cumpla uniformemente la anterior resolución.

Madrid 7 de Abril de 1822. Cayetano Valdés, Presidente. Juan Oliver y García, Diputado Secretario. Vicente Salvá, Diputado secretario ${ }^{13}$.

Es significativo, tanto el empleo del término "marcha" -no "himno"- como la utilización del epíteto "nacional". Desde luego, el himno de Riego es una marcha, pero se alude aquí a su función: "marcha de ordenanza". El decreto no establece que la nueva marcha deba sustituir a las dos marchas de ordenanza establecidas en 1769. Tampoco otorga al himno de Riego la función de "marcha de honor" reservada a la segunda. Sin embargo, al declararla "marcha nacional de ordenanza" y establecer que la orden se comunique a "todos los cuerpos del Ejército, Armada y Milicia Nacional al frente de banderas", se le otorga en la práctica las funciones que hasta ese momento cumplian las otras dos, y especialmente la Granadera. El adjetivo "nacional", por otra parte, implica un cambio sustancial en el significado simbólico del toque militar de marcha: no se trata de una marcha "de honor", es decir, vinculada a Dios, al Rey y a quien le representa, sino una música asumida como nacional, representativa por tanto de la nación como sujeto del principio de soberanía.

La proposición había sido presentada por varios diputados y estudiada por la comisión de Guerra, cuyo dictamen afirmativo, expuesto en la sesión de las Cortes del día 3 de abril de 1822, exponía las razones que apoyaban esta medida:
El tono animado y marcial de dicho himno; las grandes memorias que recuerda, lección y estímulo a los soldados ciudadanos que hoy forman y formarán en adelante el ejército español; la circunstancia de ser una marcha verdaderamente original española, cualidad que falta a las que hoy usamos, erradamente creídas nacionales; el entusiasmo con que se toca por los cuerpos del ejército; finalmente, la conveniencia de impedir por una medida general cualquier inconveniente que pueda suscitarse a pretexto de no haber orden que lo prevenga ${ }^{14}$.

Las razones eran, desde luego, convincentes y la proposición fue aceptada por unanimidad en la Cámara ${ }^{15}$. Los motivos que se aducen son muy variados. Quizá el más sorprendente es el de que las marchas utilizadas hasta entonces no eran españolas, algo que retrotrae hasta una fecha más temprana de lo que se creía la idea de que tanto la Marcha granadera como la fusilera eran prusianas $^{16}$. La "españolidad", por lo tanto, del himno de Riego jugaba una baza a su favor, así como el que tuviera letra y ésta recordara "grandes memorias", proporcionando asi "lección y estímulo a los soldados ciudadanos". Ésta es una característica propia de un auténtico "himno nacional" de la que carecian las marchas de ordenanza existentes. Pero además se alude a las cualidades de la propia música del himno, que tenía un "tono marcial y animado" y se tocaba con entusiasmo por los cuerpos del ejército. Efectivamente, como hemos analizado en otro lugari17, la música del himno, pegadiza y popular, favorecía su apropiación por parte del pueblo: su estructura melódica es clara y sencilla, como corresponde a un canto de carácter popular; el ritmo de marcha redoblada, típico del desfile de las tropas de infantería a paso ligero, es enfatizado mediante la introducción de notas largas en la primera parte -parte fuerte- del compás binario, con la que se marca el paso; los inicios de frase en anacrusa, algo muy típico en este tipo de marchas, dan impulso y vitalidad a la melodía y otorgan un carácter heroico y entusiasta al himno; además, en las frases $A$ y $B$ la anacrusa es un impulso hacia una nota más aguda que se alcanza mediante un amplio intervalo melódico, que refuerza aún más la parte fuerte del compás y enfatiza el carácter exaltado de la música; mientras en las frases A y B el amplio intervalo melódico ascendente inicial requiere un perfil descendente en el resto de la frase, necesario para equilibrarla, en la $\mathrm{C}_{1}$ correspondiente al estribillo, el perfil es ascendente, como corresponde al carácter ardiente del texto: se está jurando vencer o morir por la patria. 
A
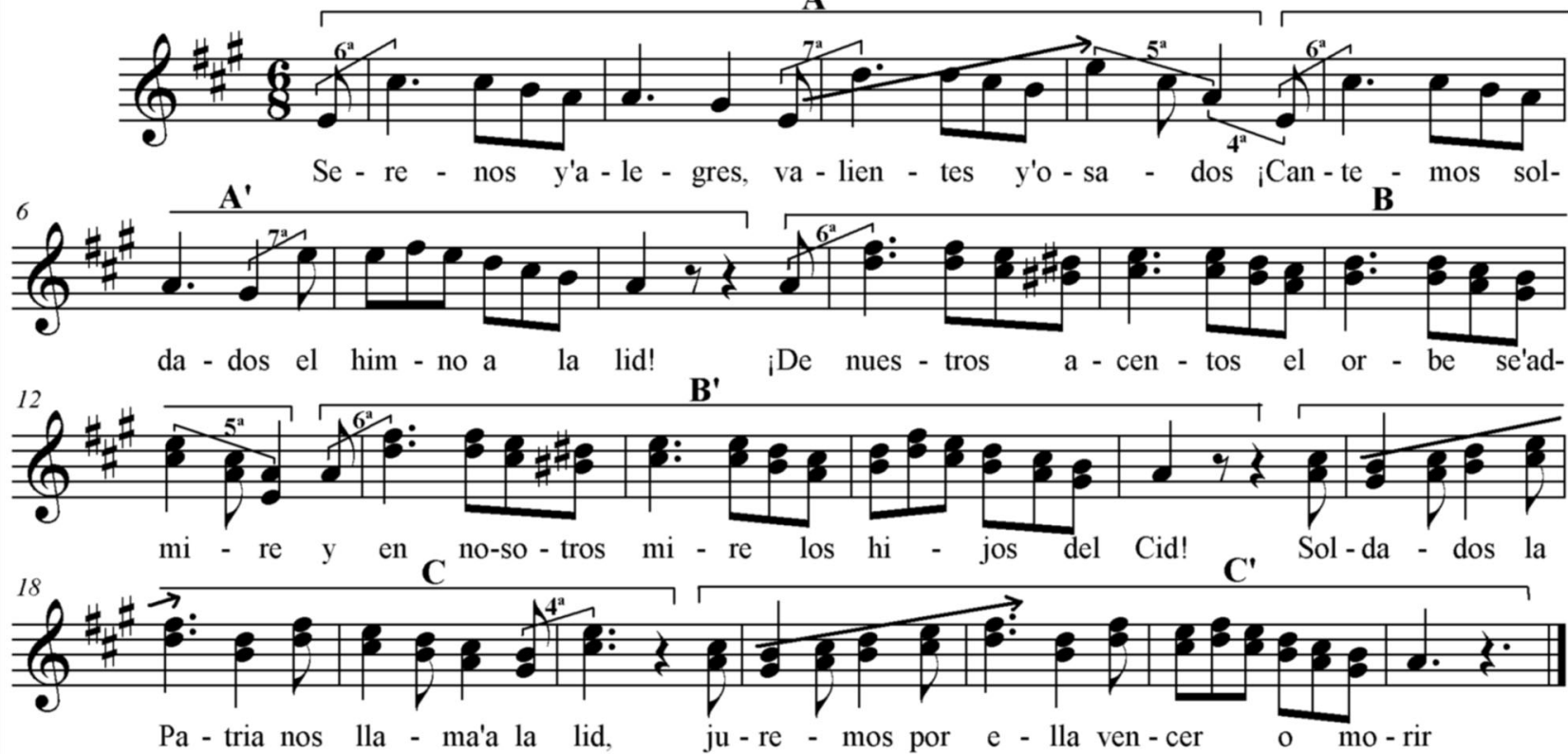

Todas estas características, además del contexto histórico en el que surge y se desarrolla este himno, explican su éxito. Pero hay una última razón aducida en el dictamen: la conveniencia de impedir "cualquier inconveniente que pueda suscitarse", por ejemplo, la oposición por parte de los partidarios del absolutismo a la interpretación de una marcha no incluida en las ordenanzas del ejército.

No es casual que este decreto fuera promulgado por las Cortes elegidas a principios de 1822 tras la denominada "revolución exaltada" de finales del año anterior. Ya desde los inicios del Trienio los liberales se habían escindido en dos grandes corrientes: los "doceañistas" o moderados, que ocuparon el poder en 1820, y los "veinteañistas" o exaltados, entre los que se contaban los revolucionarios militares y civiles que habian protagonizado y hecho posible el retorno al régimen constitucional. Aunque el nuevo gabinete encabezado por Martínez de la Rosa era de tendencia moderada, las Cortes estaban dominadas por los exaltados. Modesto Lafuente, en su Historia general de España, afirma que estas Cortes se señalaron por su marcada predilección a todos los asuntos "que fueran propicios para excitar el entusiasmo por la libertad", y entre las medidas tomadas con este propósito cita el decreto que estamos comentando, el que disponía el levantamiento de dos monumentos en Las Cabezas de San Juan y San Fernando en memoria del ejército que proclamó la Constitución y el que autorizaba a los jefes políticos a promover el entusiasmo público por medio del teatro, canciones patrióticas y convites cívicos "en los que se restablecieran las virtudes de la libertad, franqueza y unión"18.

La nueva marcha nacional tuvo muy corta vida. Con la restauración del absolutismo, tras la invasión de los Cien Mil Hijos de San Luis el 7 de abril de 1823, el himno fue prohibido y desapareció de la vida pública durante la "década ominosa". Es lógico, por tanto, que tras el fallecimiento de Fernando VII e incluso un poco antes, con los primeros indicios de una apertura política, resurgiera. Sin embargo entre 1833 y 1835, período marcado por una indefinición política que se iría resolviendo progresivamente, algunas tentativas populares por cantarlo o interpretarlo se toparon con el temor a la algarada por parte de las autoridades. Es lo que ocurrió cuando se desbordó el entusiasmo de la población en los festejos populares organizados tras la jura de Isabel II como heredera de la Corona el 20 de junio de 1833: una Real orden, dictada el 13 de julio, prohibía todas las canciones en honor a la heredera "cuya música y estribillo sea igual o parecido al himno llamado de Riego"19. También en 1834 el himno de Riego protagonizó 
graves incidentes en Cartagena, Cádiz y Granada. En la primera de estas ciudades la "audacia" del director de la orquesta del teatro al interpretar este himno durante uno de los entreactos de la función celebrada el 3 de junio le valió nada menos que una noche de cárcel ${ }^{20}$. Peores consecuencias tuvo la negativa por parte del gobernador civil de Cádiz a que se cantase, también en el teatro, el himno de Riego en la función operística celebrada el 19 de noviembre, que dio lugar a desórdenes que terminaron con la muerte de un joven trabajador de la oficina del gobernador civil ${ }^{21}$. Nos interesan especialmente las reflexiones sobre estos hechos publicadas por el periódico progresista El Mensagero de las Cortes:

El pueblo de Cádiz, liberal por sentimientos y recuerdos, pidió oír de nuevo un himno con que están enlazadas todas las memorias de antigua libertad e independencia de la patria; himno que en nuestras calles a menudo escuchamos, que en nada ofende a nuestras presentes instituciones, y que es capaz, cual ninguno, de excitar el entusiasmo patriótico tan provechoso en nuestras críticas circunstancias. Llevado de un espíritu de desconfianza, que por desgracia a menudo prevalece en los actos de nuestros gobernantes, se negó la autoridad a consentir tan moderada demanda, y de aquí resultaron las desavenencias. ¡Cuánto más cuerda fue la conducta de Luis Felipe, que entonando él propio la Marsellesa (expresión de las ideas republicanas) la despojó de su carácter, y adoptó todas las glorias de la Nación para su gobierno! ¿Estamos por ventura tan unidos los españoles que convenga aumentar los gérmenes de la discordia, repudiando inocentes recuerdos de lo pasado? ¿Estamos en estado tan tranquilo y seguro, que convenga impedir repetir el juramento de vencer o morir por la Patria? ${ }^{22}$

Es interesante destacar que Evaristo San Miguel era uno de los fundadores de este periódico, que estaba dirigido por Antonio Alcalá Galiano, quien también había participado en la conspiración de 1820 y era diputado -en las filas de los exaltados- en las cortes que habían proclamado el himno de Riego "marcha nacional de ordenanza". Las ideas que subraya el texto recuerdan mucho a las que habian apoyado la aprobación del decreto: se trata de un himno "con que están enlazadas todas las memorias de antigua libertad e independencia de la patria"; es además un himno popular, que se escucha a menudo en las calles y "es capaz, cual ninguno, de excitar el entusiasmo patriótico" -no olvidemos que un año antes había comenzado la primera
Guerra carlista-. En resumen, reunía todas las condiciones de un auténtico himno nacional. El autor del texto advierte también del riesgo de impedir su interpretación -algo que provocaría la desunión- y elogia la actitud de Luis Felipe en Francia, que en lugar de prohibir La Marsellesa se había servido de ella 23 .

El gobierno no sólo desoyó estos consejos, sino que, a pesar del clamor popular -el himno era interpretado masivamente por parte del pueblo y de los batallones del ejército-, dio un paso más prohibiendo en los actos militares, mediante una Real orden circular promulgada el 6 de marzo de 1835, los toques de guerra arbitrarios, vivas y aclamaciones no mandados en la ordenanza. Transcribimos por su interés el texto de la Real orden, firmada por el entonces ministro de la guerra, el general Jerónimo Valdés:

Consiguiente a la circular expedida con fecha 4 del actual de orden expresa de S. M. por este Ministerio de mi cargo, sobre el mantenimiento de la más severa disciplina y subordinación en todos los Cuerpos e institutos que componen la fuerza armada, me manda S. M. Ilamar particularmente la atención de $\mathrm{V}$. sobre varios abusos que han principiado a introducirse, y que conviene cortar en su origen antes de que lleguen a producir fatales consecuencias, de que desgraciadamente tenemos experiencia. Con este importante y trascendental objeto se ha servido S. M. resolver: 1. ${ }^{\circ}$ Que se prohiban absolutamente y sin excusa ni excepción los toques de guerra de que arbitrariamente usan algunos de dichos Cuerpos en los actos de servicio, porque aunque parezcan indiferentes en sí mismos, son sin embargo una verdadera transgresión de las Ordenanzas y Reglamentos militares, por no ser los que en unas y otros están prescritos; $2 .{ }^{\circ}$ Del mismo modo prohibe $S$. M. que por motivo ni pretexto alguno se den vivas ni aclamaciones de ninguna especie, no tan sólo porque en ello se falta de hecho a la Ordenanza, sino porque esa viciosa práctica, tan agena del severo carácter militar, relaja la subordinación y la disciplina, y familiariza las tropas con el desorden; y 3..$^{\circ}$ Por lo mismo, y aun con mayor razón, ordena S. M. que en ningún caso ni circunstancia se permita ni tolere que las músicas, y mucho menos las tropas, entonen canciones de ninguna clase, como se ha verificado en algunos, si bien en muy pocos Cuerpos, cuya conducta ha merecido el desagrado de S. M. De la exacta observancia de todas estas disposiciones serán personalmente responsables los Gefes, a tenor de lo que en la referida circular se previene; esperando S. M. del zelo y energía de V. el más 
puntual cumplimiento de esta Real resolución, en que tanto se interesan el bien del Estado, el buen nombre del Ejército, y el mejor servicio de S. M.; de cuya Real orden lo digo a V. para su inteligencia y efectos indicados.

Madrid 6 de Marzo de 1835. Valdés ${ }^{24}$.

En octubre de 1835, desde las páginas de La Revista Española, periódico que se había refundido el 1 de marzo de ese año con El Mensagero de las Cortes bajo la dirección de Alcalá Galiano, se instaba al gobierno a declarar el himno de Riego marcha nacional, argumentando que la orden prohibiendo el toque de himnos había contribuido a desalentar al ejército y había tenido funestas consecuencias ${ }^{25}$ :

HIMNO DE RIEGO. Varias personas que tienen dadas pruebas y testimonios irrecusables de su amor y sacrificios por la causa de la libertad, nos suplican llamemos la atención sobre el sentimiento con que se nota que las músicas de los diversos cuerpos de la Guardia Real y demás de la guarnición no tocan himnos ni canciones patrióticas, que tanto agradan al público y que tanto inflaman a los soldados españoles, soldados en el día de la libertad, no de la tiranía. Esperamos que el señor ministro de la Guerra, conde de Almodóvar, que tantas pruebas tiene dadas de civismo y de convicción de que el "entusiasmo no es un vapor", se servirá inducir el ánimo patriótico de la liberal Reina Gobernadora para que se digne decretar que se permita en todos los diferentes cuerpos del ejército el toque de canciones patrióticas, y que asimismo accediendo al deseo tanto tiempo ha pronunciado por la nación entera, declare el HIMNO DE RIEGO MARCHA NACIONAL Y DE ORDENANZA, quedando por consiguiente derogada la real orden de 6 de marzo de este año, que trata sobre la materia ${ }^{26}$.

La petición siguió siendo reiterada durante el año siguiente. Mientras tanto, el himno se entonaba con entusiasmo en calles y teatros, recibiendo letras alusivas a los acontecimientos bélicos. Sin embargo, no volvió a ser proclamado marcha nacional. Desde nuestro punto de vista, se perdió en ese momento una oportunidad histórica. En un momento de construcción del estado liberal en España, la necesidad de mantener la unidad de todas las tendencias liberales frente a un enemigo común, el carlismo -identificado con el absolutismo-, llegó a diluir las connotaciones exaltadas o progresistas del himno de Riego. El pueblo lo adoptó espontáneamente como himno liberal y, como consecuencia, patriótico. De ahí a proclamarlo "nacional" sólo había un paso. Sin embargo, las decisiones políticas tomadas por el gobierno, fruto del temor a la insurrección y probablemente de presiones políticas, terminaron convirtiendo el himno en un arma de combate de los progresistas contra el propio gobierno moderado.

Encontramos un claro ejemplo de la "radicalización" del significado del himno, así como de la influencia de la música en el desarrollo de los acontecimientos políticos, en el Motín de La Granja, que tuvo lugar el 12 de agosto de 1836. Según la narración de uno de los protagonistas del motín, Alejandro Gómez, sargento del regimiento de granaderos de la Guardia Real, la chispa que encendió la sublevación fue precisamente la prohibición de tocar el himno de Riego:

El día 12 de agosto de dicho año de 1836, por la mañana, se presentó un paisano, que era nacional de caballeria de Madrid, en el café del Teatro, y a pesar de que por los periódicos sabíamos la mala situación de la corte, nos manifestó que por no dejarse desarmar había salido huyendo de la corte, añadiendo que era tal la agitación por todas partes, que se había desarmado la Milicia Nacional. Tales noticias produjeron en nosotros un sentimiento de indignación contra aqueIla situación, sólo justificada por un Gobierno anti-liberal. En tal estado los ánimos, dióse orden general comunicada al medio día por el comandante general del Real Sitio, conde de San Román, prohibiendo con graves penas que se cantasen canciones patrióticas, y mandando también que las músicas y bandas no tocasen otras marchas que las de ordenanza. Se necesitaba un pequeño motivo, en nuestros ánimos excitados, y parece que aquella orden le llevaba en sí, pues toda la guarnición la recibió tan mal, que produjo instantáneamente sus resultados. Aquel dia, como se sabían los sucesos de Madrid, fue el punto de reunión natural el camino de éste, por la curiosidad más bien de saberse noticias; y a pesar de la prohibición, los soldados cantaban con más entusiasmo que nunca, sin que nadie se lo reprobase ni prohibiese. En un gran grupo de sargentos de todas las armas, estaba también el tambor mayor de la Guardia provincial, y se le invitó por muchos a que aquella tarde en la lista tocase el himno de Riego. Tenía lugar ésta a las seis y media, y la música acostumbraba a tocar diferentes piezas, reuniéndose a sus inmediaciones muchos curiosos de la población. Formados ya para este acto, y al tiempo de romper la marcha el batallón para volver al cuartel, y dirigiéndose a la banda el tambor mayor, temió éste, y la encargó tocase la marcha granadera; 
pero los pífanos acompañaron ésta con el himno de Riego. Apenas se apercibió el comandante, mandó hacer alto al batallón y callar a la banda; después, con descompuestas voces de reprensión, lo hizo entrar en el cuartel, poniendo a toda la banda arrestada, y en un calabozo al tambor mayor, y como comprendiese el disgusto de todos, dispuso también reforzar la guardia de prevención, y que todos los oficiales se quedasen en sus compañías, prohibiendo la salida a los sargentos. La coincidencia de estar anunciada para aquella noche en el teatro la comedia titulada A las diez de la noche o los síntomas de una conjuración, hizo se escogiese esta hora para pronunciarse, y el redoble de silencio fue la señal para llevarlo a efecto ${ }^{27}$.

En los años siguientes continuarian los incidentes relacionados con su interpretación, especialmente a partir de 1845, durante el gobierno moderado de Narváez, lo que demuestra que "venció" el carácter progresista del himno, algo que haría imposible que fuera asumido como himno nacional.

\section{De la Marcha Granadera a la Marcha Real}

Hemos afirmado más arriba que es problemático considerar a la Marcha granadera como himno o marcha nacional en la primera mitad del siglo XIX. Durante el reinado de Fernando VII esta marcha de ordenanza tuvo muy poca presencia pública. El régimen político, por otra parte, no favorecía que el pueblo pudiera identificarse con una música que representaba el poder absoluto del monarca. Con Isabel II la monarquía pasó a ser constitucional, lo que otorgaba a la marcha un mayor simbolismo institucional. Sin embargo, la prohibición sistemática del himno de Riego por parte de los gobiernos moderados tuvo como consecuencia que la Marcha granadera se impregnara también de connotaciones partidistas. En el relato de los sucesos de La Granja transcrito más arriba se puede ver una "pugna" entre ambas marchas: el tambor encargó que se tocase la granadera, pero el pífano tocó el himno de Riego, lo que provocó el arresto de la banda. Esta pugna está cargada de simbolismo: al no permitirse tocar el himno de Riego, himno considerado nacional por los liberales progresistas, como marcha del ejército, la marcha granadera acabaría siendo considerada por éstos como símbolo del moderantismo e incluso del absolutismo.
En realidad ambas marchas respondian a dos ideas de nación. Para los moderados lo "español" estaba identificado con la monarquía -defendida como pieza insustituible en el nuevo ordenamiento político, institucional y jurídico del régimen liberal-y la religión. Para los exaltados, y luego los progresistas y demócratas, la soberanía nacional residía en el pueblo y las Cortes, siendo la monarquía algo accidental. La Marcha granadera era una marcha "de honor", reservada al Santísimo Sacramento y al Rey/Reina y a quienes le representaran; el himno de Riego una marcha popular de combate que exaltaba el patriotismo y la idea de libertad frente al absolutismo. Ambas ideas, sin embargo, no eran incompatibles. El liberalismo doctrinario, que trataba de armonizar el orden tradicional y los principios liberales y materializado sobre todo en las constituciones de 1845 y 1876, defendía el principio de la soberanía compartida: la monarquía y la nación eran entes históricos inseparables y ambos igualmente depositarios de la soberanía ${ }^{28}$. Las dos marchas, por lo tanto, no tenían por qué ser incompatibles, como sí lo eran para los absolutistas y los republicanos. Sin embargo, como afirma Riquer, la élite política y militar liberal actuó desde 1843 sólo preocupada por delimitar y moderar la revolución y por evitar ser desbordada por los radicales demócratas, en detrimento de la creación de un consenso social y de la articulación de políticas tendentes a reconstruir la unidad nacional tras la sangrienta guerra carlista $^{29}$. Una de las consecuencias de esta política defensiva fue la prohibición del himno de Riego, medida que no favoreció precisamente la unidad nacional.

A pesar de todo, la Marcha granadera adquirió un peso público muy importante y cierto consenso social durante el reinado de Isabel II, pasando a ser denominada Marcha Real. A partir de 1843 España entró en una etapa de mayor estabilidad, superada la guerra carlista y liquidadas las regencias. Los moderados empezaron a imponerse. La marcha acompañaba las entradas y salidas, los actos y festejos a los que acudia la reina, cuya vida pública era intensa. En la medida en que la figura de la reina era percibida como fundamento de la nación, la marcha real que acompañaba su presencia podía ser más fácilmente percibida como símbolo nacional. En esos años el entusiasmo del pueblo al escuchar la marcha real es puesta de relieve en textos como el siguiente, que relata la asistencia de la reina a una representación operística en mayo de 1843: "Al entrar S. M. en él [palco], la orquesta tocó la marcha real y un sentimiento de amor y de entusiasmo se pintó en todos 
los semblantes"30. El "amor" y el "entusiasmo" que provoca la música se pueden interpretar como fruto de la emoción colectiva ante la aparición de la reina, pero ¿responden también a un sentimiento de cohesión nacional en torno a la realeza? ¿Se trata de un relato condicionado por la ideología conservadora del periódico? Es difícil responder a estas cuestiones. El Heraldo, creado en 1842, fue el diario conservador más representativo de la década moderada, defensor de la monarquía constitucional y contrario al partido progresista del general Espartero, que ocupaba en ese momento la regencia.

Un año más tarde El Pensamiento de la Nación, periódico moderado redactado casi íntegramente por Jaime Balmes, criticaba el "aparato semi-monárquico" de que se estaban invistiendo los capitanes generales de algunas provincias, que salian precedidos por dos batidores y seguidos de una gran escolta de caballería con sable en mano y a los que "se toca marcha real"; "¿qué se reserva entonces para la Reina?" ${ }^{\prime 1}$. Este mismo abuso sería denunciado reiteradamente en las décadas siguientes, como veremos, especialmente por los medios moderados, ya que suponía una peligrosa descentralización al diluir prerrogativas reservadas a la reina como fundamento de la nación.

Otro texto que destaca la emoción de la muchedumbre, que en este caso "corea por la primera vez nuestra antigua marcha real", es el larguísimo relato de la inauguración del ferrocarril de Madrid a Aranjuez, publicado por La España el 11 de febrero de 1851, del que extractamos un fragmento:

SS. MM. pasaron con toda pompa y acompañadas del presidente del Consejo de ministros señor Bravo Murillo y demás consejeros de la Corona, a ocupar el regio dosel. El señor Cardenal estaba ya delante del altar. Grandes músicas poblaron los aires de armonía, y con agradable sorpresa numerosas voces coreaban por la vez primera nuestra antigua marcha real ${ }^{32}$.

Un indicio evidente de la popularidad de la marcha es su publicación en 1852 junto con la fusilera, anunciadas por el almacén de música de Lodre como "Marcha real granadera y fusilera, ejecutada en los teatros y por la guarnición de Madrid".

Sorprende, vistos estos datos, la sustitución de las dos antiguas marchas de ordenanza por una nueva en el Regla- mento de táctica de la infantería aprobado por Real orden de 18 de octubre de 1850, durante el gobierno presidido por Bravo Murillo, hecho sobre el que pide explicaciones en 1851 la Revista Militar:

Conocianse y estaban en práctica hasta hace muy poco tiempo dos [marchas de infanteria], que se distinguian con los nombres de marcha granadera y marcha fusilera: cada una tenía su objeto y aplicación, sus recuerdos, y por consiguiente sus títulos para ser respetada siquiera hasta que una razón más fuerte que las que les habian dado origen y hecho conservarlas viniese a destruirlas.

Sin embargo, la primera parte del reglamento táctico aprobado por el gobierno durante el tiempo que dirigió el arma de infantería el general O'Donnell echa abajo las antiguas marchas sustituyéndolas con una, cuya ventaja no hemos podido comprender. En efecto, buscándola bajo el punto de vista de la conveniencia táctica, única razón que en este género de cosas puede autorizar a destruir lo antiguo, hemos examinado si el compás de la marcha moderna es más acomodado al paso natural de nuestros soldados, si marchan con él con más soltura, con más facilidad: en esto creemos se ha perdido bastante. Juzgamos, pues, entonces, que la mayor velocidad que en el día quiere darse a las evoluciones lo mismo que a las marchas ordinarias, sería el fundamento para adoptar una nueva más acomodada a estos principios; pero tampoco es así, pues la marcha admitida es de menor número de compases al minuto. ¿Cuál es, pues, la razón? [...] $]^{33}$.

Es interesante la relación que establece el autor del artículo entre la supresión de las antiguas marchas y el general 0'Donnell, director general de Infantería en el momento de aprobación del reglamento táctico. O'Donnell protagonizaría en 1854 el golpe de estado que daría lugar al Bienio Progresista. En cualquier caso, no conocemos los motivos que llevaron a eliminar las antiguas marchas; por otra parte, la marcha real siguió siendo interpretada por orquestas, bandas e incluso la guardia real; y en 1853 el gobierno tuvo que dar marcha atrás, promulgando una Real orden que restablecía la Marcha granadera:

S. M. la Reina (O. D. G.) ha tenido a bien resolver que en lugar de la marcha prescrita por el Reglamento de táctica de la infantería, aprobado por Real orden de 18 de Octubre de 1850, y que actualmente usan los Cuerpos de su arma, sólo se toque en lo sucesivo, tanto por dichos Cuerpos como 
por todos los demás del Ejército, la antigua española, vulgarmente conocida con el nombre de granadera; debiendo arreglarse a su compás, que continuará siendo de 104 pasos por minuto, los pasos dobles y demás toques y piezas de música que usen las bandas.

De Real orden, comunicada por dicho Sr. Ministro, lo traslado a V. E. para su conocimiento y a fin de que no se permita el menor abuso en este punto. Dios guarde a V. E. muchos años. Madrid 5 de Setiembre de 1853. El Subsecretario, Eduardo Fernández San Román ${ }^{34}$.

El Heraldo, especialmente, se felicitaba de la decisión del ministro de la Guerra, el general Lersundi, y aprovechaba para resaltar la antigüedad de la Marcha granadera, la "antigua marcha española" que, según el articulista, "era la usual y corriente nada menos que en la época de los Alfonsos, siendo ella la que sonó en la batalla de [las Navas de] Tolosa". El artículo recibió numerosas críticas del resto de la prensa debido a la falta de rigor de su contenido, definido como "ridículo". Sin embargo, nos interesa destacar el hecho de que en esta época se empieza a defender la marcha real por razón de su antigüedad $y$, por lo tanto, como símbolo de una tradición inherente a la nación española. El texto la define como "objeto venerable, como una institución, en suma, que enlaza el presente con lo pasado, concurriendo así a formarse el culto, la tradición que son necesarios para establecer el verdadero espíritu militar" ${ }^{135}$.

\section{Marcha Real versus Himno de Riego}

Tras la revolución y el golpe de estado de 0'Donnell en 1854, que dio lugar al Bienio Progresista presidido por Espartero, se produce un resurgimiento del himno de Riego, interpretado sin trabas junto a la Marcha real. Así vemos que ocurre, por ejemplo, al entrar en Toledo el 29 de octubre de 1854 como inspector de la Milicia ciudadana el general Evaristo San Miguel, definido por el periódico progresista La lberia como "héroe de la libertad": "se le recibió con música que tocó, primero marcha real, y en seguida el himno del inmortal Riego"36. También en el acto de inauguración de la fuente monumental dedicada en Barcelona al marqués de Campo Sagrado ${ }^{37}$ organizado en junio de 1856 por el Ayuntamiento de la Ciudad condal, presidido por el gobernador de la provincia, "las músicas de los piquetes tocaron, las unas la marcha Real española y las otras el himno de Riego"38. Tanto en uno como en otro caso la marcha real no está asociada directamente a la reina, lo que demuestra que su función y simbolismo se había ampliado. Sin embargo, en abril de 1855 Espartero fue muy criticado por algunos sectores porque en una revista de tropas se le recibió con la marcha real. El periódico moderado La España esgrimía las ordenanzas para argumentar que a un capitán general sin mando militar no le correspondían esos honores: "sobre todo no creemos que en ningún caso y por ningún concepto la marcha real debe tocarse sino al soberano"39; mientras que El Correo universal justificaba el toque aduciendo que esta marcha no estaba reservada "oficialmente" a los reyes ${ }^{40}$. Esta polémica manifiesta el diverso simbolismo de ambas marchas: la de Riego es considerada "himno nacional", la granadera es la "marcha real". Aunque el simbolismo de ésta se concrete cada vez más en términos de representación de la nación española, al no ser declarada en ningún momento oficialmente marcha nacional su utilización y significación quedan expuestas a usos e interpretaciones diversos. Muy significativa, en este sentido, es la metáfora empleada en La lberia en 1859 para definir la algarabía política reinante en el parlamento, descrita como "una orquesta, cuyos músicos tocan unos el himno de Riego, otros la marcha Real y otros la Pitita, y cada uno en distinto tono"41.

Una de las consecuencias de la no oficialización de la Marcha real, es decir, de la inexistencia de un himno o marcha que representara a toda la nación, y no únicamente al rey o a la reina, será la cada vez más continua petición de creación de un himno nacional español. A partir de los años cincuenta $y$, sobre todo, sesenta, hay una eclosión de himnos nacionales en Europa y América cuyos ecos llegan a España en forma de partituras ${ }^{42}$ y relatos heroicos: La Marsellesa, el himno ruso, el polaco, el italiano de Garibaldi, el prusiano, son entonados por cientos o miles de ciudadanos en situaciones difíciles o victoriosas. Sin embargo, los españoles carecen de un himno con el que cantar las victorias de las tropas españolas en la Guerra de África, desarrollada entre 1859 y 1860 . Éste es el motivo que induce a Un filarmónico proyectista a proponer al ministerio de Fomento la convocatoria de un certamen para componer un himno nacional "que exprese el entusiasmo y el patriotismo que anima a todos los españoles con motivo de la guerra"43. La idea es recogida por el periódico demócrata La Discusión y apoyada por La lberia, pero des- 
de las páginas de La España se rechaza la propuesta con el argumento de que "los grandes himnos nacionales no reconocen autor; son como nuestras canciones populares [...]. Nuestro grande, y de otros pueblos envidiado, himno nacional, la marcha real, ha llegado a nosotros sin fecha ni nombre de autor; para nosotros, su mayor encanto está en el misterio de su origen"44. Por primera vez encontramos la expresión "himno nacional" aplicado a la Marcha real.

Aunque la propuesta no fue recogida por el ministerio, el Conservatorio de Madrid convocó un concurso público que ganó el músico José Gabaldá con el "himno nacional" El grito de la patria, dedicado "al invicto duque de Tetuán y al bravo ejército español". El nuevo himno tuvo apenas unos meses de gloria, siendo "tocado con entusiasmo por todas las músicas de nuestro valiente ejército de África y de la Península"45. Pero los himnos representativos fueron, como siempre, la Marcha real y el himno de Riego. Al compás de la primera se recibe a O'Donnell, general en jefe del ejército, en suelo africano; a los sones del segundo se festeja en distintas ciudades la entrada de las tropas españolas en Tetuán y se recibe en Valencia al ejército victorioso:

La tropa, sin orden de formación, apenas podía caminar abrazada por los paisanos, las espadas de los oficiales y los fusiles de los soldados se hallaban adornados con ramos de flores y de laurel, otros llevaban palmas, en muchos rosos se veían coronas, los dos jefes se hallaban materialmente cubiertos de flores, teniendo algunas personas que llevar del diestro a los caballos, la bandera apenas podía contener las coronas con que la adornaban a porfía, muchos repartían puros y pasteles a todos, y las músicas completaban tan mágico cuadro haciendo oír el himno más bello de la música moderna, el himno de Riego, que de hoy más no será exclusivo de este o del otro partido, sino que será el verdadero himno nacional ${ }^{46}$.

Desde ese momento vuelve a reabrirse la pugna de him$\operatorname{nos}^{47}$, con el mar de fondo de una inestabilidad política que culminaría en la revolución de 1868.

En 1864 el crítico musical de La España José María de Goizueta recoge y hace suya la idea de adoptar como himno nacional la Cantiga n. ${ }^{\circ} 14$ de Alfonso X el Sabio parafraseada por Eslava, obra que había tenido un enorme éxito en los conciertos de la Asociación Artístico-musi- cal de Socorros Mutuos. Según Goizueta, España carecía de himno nacional y la composición propuesta era una composición grandiosa, comparable a la obra de Haydn adoptada como himno nacional austriaco ${ }^{48}$. Como es lógico, la idea no prosperó; La lberia tachaba la propuesta de "delirio" y aprovechaba para manifestar nuevamente que "el pueblo español, liberal en su mayor parte, tiene ya su Himno nacional": el himno de Riego, "ese himno que suena tan mal en los oídos de los reaccionarios y que despierta en nuestros corazones los sentimientos de libertad y de patria"49. Al mismo tiempo, el descrédito de Isabel II -según Riquer, al no actuar como árbitro de las distintas facciones políticas impidió que la corona fuera vista y aceptada como la encarnación de la nación ${ }^{50}$ - favoreció la desvirtuación de la Marcha real. Fue especialmente criticado en 1863 y 1864 el general Concha -marqués del Duero-, general en jefe del primer ejército, por hacerse tocar la marcha real al pasar revista a las tropas. Pero fueron entonces los sectores progresistas, que acuñaron el apodo de el Rey de las Afueras, quienes aprovecharon la ocasión para desacreditar al general, hasta el punto de afirmar un periódico catalán: "es posible que esta tontería sea más poderosa para derribarlo, que los juiciosos artículos que se han publicado contra la inconveniencia de la continuación del primer ejército"51.

\section{Los himnos del Sexenio Democrático}

En septiembre de 1868 estalla la revolución que destrona a Isabel II y marca el inicio del Sexenio Democrático o Revolucionario. Inmediatamente comienzan a proliferar los "himnos nacionales" compuestos por diversos músicos para festejar el triunfo de la revolución y la caída de los borbones, como ocurre con el himno nacional iAbajo los borbones!, letra de Antonio García Gutiérrez y música de mismo Arrieta que había sido maestro de canto de la reina Isabel II52, el Himno nacional de Federico Chueca o el himno nacional iViva la libertad! de Manuel Fernández Grajal, entre otros muchos. La acuñación de la expresión "himno nacional", que sustituye a la expresión "himno patriótico" imperante durante el primer tercio del siglo XIX, denota un cambio de mentalidad: de la idea de "patria" se ha pasado a la de "nación"; pero también indica que no existe aún una clara identificación del "himno nacional" con el himno oficial representativo de la propia nación. 
También ahora es distinta la situación de la Marcha real: era tanta la costumbre de interpretarla por parte de bandas y charangas, que con ella se aclama a la revolución y a sus artífices, lo que hace que algunos medios avisen: "¡Silencio! Algunos mal acostumbrados cornetas del pueblo tocan la marcha real a las banderas de la revolución. Valiera más que se callaran"53. Sin embargo, no todo eran "cornetas del pueblo": cuando el general Prim, ministro de la Guerra, pasa revista a la guarnición de Madrid, las bandas de música de los batallones también tocan la Marcha real, que empieza a ser denominada por algunos periódicos marcha nacional, lo que provoca protestas de uno y otro lado. Ante esta situación, Prim encarga una nueva marcha a José Squadrani, director de la banda del segundo regimiento de ingenieros. Esta marcha, publicada bajo el título Nueva Marcha Naciona ${ }^{54}$ y estrenada el 11 de febrero de 1869, día de la apertura de las Cortes constituyentes, fue la que sustituyó por orden gubernamental a la marcha real en todos los actos en los que se tocaba ésta.

La nueva marcha fue un fracaso: prácticamente todo el mundo reconoció que era muy mala. Basta examinarla para comprobarlo: presenta una melodía sin gracia, una armonía muy simple, sin apenas elaboración y un ritmo excesivamente lento que hace pesada la marcha.

Pocos días después de su estreno, El Universal lanzaba la idea -apoyada por muchos otros medios- de abrir un concurso para la composición de una marcha nacional "digna de la Revolución". En esta ocasión el gobierno asumiría la idea, pero... un año más tarde. Mientras tanto, se sucedian los incidentes protagonizados por la Marcha real, lo mismo que había ocurrido treinta años antes con el himno de Riego, y se buscaban soluciones de compromiso para los actos oficiales e institucionales. Así, en la fiesta nacional del 2 de mayo las bandas de música de ejército y las de voluntarios estrenaron la Gran marcha nacional española de Chueca, dedicada a las Cortes Constituyentes, y en julio del mismo año la dirección general de Infantería recomendaba a los jefes de los cuerpos una nueva marcha nacional granadera compuesta por Teodoro Santafé Laguna para sustituir a la Real. Lo que Ilama la atención en todo este proceso es que no se plantee ya en medios oficiales la alternativa del himno de Riego, a pesar del renovado interés que despierta en estos años. Incluso cuando el general Nouvilas, capitán general de Cataluña, durante una revista de las fuerzas de la guarnición hace callar a algunas bandas que empezaban
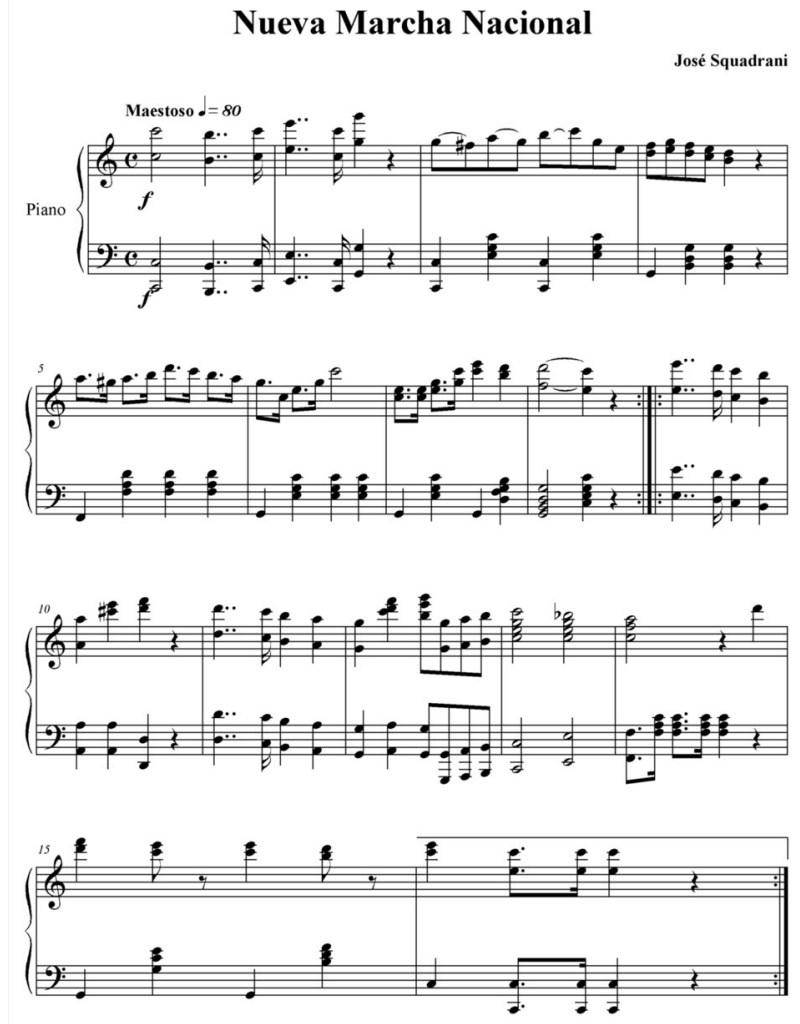

a tocar la marcha real y les da la orden de tocar el himno de Riego, el periódico satírico Gil Blas, de orientación republicana, publica el siguiente comentario:

El general Nouvilas no quiere que las músicas le toquen la marcha real.

¡Este general me parece muy razonable!

En cambio de la marcha real ha pedido que le toquen el himno de Riego.

Esto ya no sólo es más razonable, sino más divertido. Sin embargo, se puede dar el caso de un general, que para hacer la competencia al general Nouvilas, haga que las músicas le toquen la jota cuando pase revista a las tropas ${ }^{55}$.

En septiembre de 1870 el Ministerio de la Guerra convoca un certamen para la composición de una Marcha nacional que sustituyera a la Marcha real, que había "dejado de tocarse por las músicas militares después de la Revolución de 1868". Las bases, publicadas en la Gaceta de Madrid del 12 de septiembre, establecen que la marcha "habrá de ser a paso regular, en compás de compasillo, de estilo 
brillante y majetuoso". Estas características responden más a una marcha de honor, al estilo de la granadera, que a una marcha redoblada de ritmo animado como la de Riego. El jurado estaba formado por tres de los músicos españoles de mayor renombre de la época: Eslava, que renunciaría por motivos de salud siendo sustituido por Saldoni, Arrieta y Barbieri. Pocos días antes de que terminara el plazo de presentación de composiciones el crítico Goizueta, desde las páginas de La Época, auguraba que se presentarian muchas composiciones pero que ninguna tendría "el mérito de la antigua marcha real", que tenía en su favor, "además de la majestad del ritmo, una melodía fácil de retener, porque es sencilla, distinguida", y opinaba que lo que debería hacerse es armonizar la marcha antigua ${ }^{56}$. ¿Estaba preparando el terreno a una decisión ya tomada? Sea como fuere, Goizueta acertó: a pesar de que se presentaron 447 composiciones, el jurado dejó desierto el concurso, aduciendo en el dictamen fechado el 8 de diciembre las siguientes razones:

Desgraciadamente el asunto del certamen es de los más difíciles; porque en los cantos nacionales, aparte de su mayor o menor bondad artística, entra por mucho la significación que les presta la costumbre o el capricho de los pueblos; y cuando, como en España sucede, todos estábamos acostumbrados a considerar como símbolo de las Majestades divina y humana los nobles y sencillos acordes de nuestra antigua marcha real (que, dicho sea de paso, es artísticamente de lo mejor y más apropiado que puede inventarse), no hay que extrañar que tales consideraciones hayan podido contribuir a que el genio de nuestros compositores no levante su vuelo a la altura conveniente, sintiéndose cohibido por el recuerdo de la referida "Marcha real", especie de espada de Damocles pendiente sobre su cabeza.

[...] En resumen: el Jurado, después de un detenido examen, ha acordado por unanimidad que entre todas las marchas presentadas, si bien hay muchas dignas de aprecio, no hay ninguna que merezca los premios ofrecidos ${ }^{57}$.

En definitiva, en esta decisión pesaba más la costumbre o tradición -las ideas de "símbolo" y "antigüedad" lo testimonian-, que incluso determina la valoración artística de la música -"nobles y sencillos acordes"- por parte de tres músicos tan reconocidos, que la supuesta asociación de la marcha con la dinastía borbórnica derrocada. Tras un juicio tan determinadamente partidario de la antigua marcha, de la que se llega a decir que es "artísticamente de lo mejor y más apropiado que puede inventarse", sería muy difícil llegar a sustituirla. Por otra parte, sólo veinte dias antes de este dictamen el Parlamento había elegido a Amadeo de Saboya como nuevo rey de España, por lo que se podía mantener sin muchos problemas la marcha real, a pesar del cambio de dinastía. $Y$ esto es lo que finalmente ocurriría tras un nuevo "fracaso": el 30 de diciembre de 1870 se estrenó una nueva Marcha Real con motivo de la llegada a España de Amadeo I, compuesta por el músico mayor José Ruiz Muñoz. La prensa se hizo enseguida eco del sentir popular: "La marcha real que se ha tocado ha parecido a todo el mundo de pésimo gusto y muy inferior a la antigua marcha real"58. El Imparcial llamaba la atención además sobre el desprecio que suponía a los músicos españoles que habian presentado composiciones al concurso el hecho de aprobar "la primera marcha que se presente, aunque sea tan mala como lo es la que hoy tienen algunos por marcha real" 59 . El rey decidió, finalmente, volver a declarar marcha nacional española la Marcha granadera en lugar de la de Squadrani, que a pesar de los acontecimientos relatados no había llegado a sustituirse de manera oficial.

El 11 de febrero de 1873 renunció al trono Amadeo de Saboya y la Asamblea Nacional proclamó la República, quedando nuevamente la marcha real sin razón de ser, a pesar de que seguía siendo interpretada por la fuerza de la costumbre. Es muy significativo, a este respecto, el suceso ocurrido en Pamplona en febrero de 1873 cuando Pavía, general en jefe del ejército que combatía contra los carlistas, pasó revista a las tropas y una de las bandas comenzó a tocar la marcha real; "pero cuando llegó enfrente de los nuevos voluntarios (antiguos republicanos), éstos han protestado, y Pavía, después de darles mil satisfacciones, ordenó que cesase la marcha real y se tocase el himno de Riego"60. Sin embargo, el nuevo régimen político no llegó a sustituir oficialmente la marcha real, que pasó a ser denominada marcha nacional en 1874, durante el gobierno de concentración presidido por Serrano. Por otra parte las circunstancias de la proclamación de la república no favorecieron un movimiento popular como el del 68, por lo que no encontramos una proliferación de himnos como la de cinco años atrás. El omnipresente Chueca compuso un nuevo himno de bastante éxito: el Himno nacional republicano dedicado "al ciudadano Emilio Castelar". También tuvo mucha fortuna el Primer Himno de la República española compuesto por "el ciudadano Amalio Ramiro"61. Además, la sociedad El Fomento de las Artes, de inspiración 
krausista ${ }^{62}$, convocó un concurso "para la composición de un Himno nacional de la República".

\section{La marcha de Cádiz, último "himno nacional" DEL SIGLO XIX}

La restauración borbónica, que proclamó rey a Alfonso XII el 29 de diciembre de 1874, devolvió a la Marcha granadera su primitivo carácter de Marcha real borbónica. Sin embargo, en ese período se había acentuado la contradicción entre su función de "marcha de honor", establecida por las ordenanzas militares, y su significado simbólico de "marcha nacional". Esta contradicción, origen de numerosas polémicas durante el último tercio del siglo XIX, se manifiesta, por ejemplo, en las críticas a Cánovas del Castillo por permitir que las bandas le recibieran con la marcha real. Encontramos críticas en medios ideológicamente contrarios, por razones diferentes en cada caso. Mientras que los diarios El Globo -de ideología republicana-, La lberia o El País aprovechaban esta circunstancia para atacar a Cánovas ${ }^{63}$, El Correo Militar advertía de que "así, de atentado en atentado contra las claras y terminantes disposiciones de la Ordenanza, vienen los conflictos y la anarquía gubernamental"64, y La Época declaraba que la marcha real "debiera cambiar su nombre por el de Marcha nacional, ya que a sus sones se recibe y despide, no sólo a la Real familia, como antes sucedía, y para la cual fue hecha, sino a todos los que representan una autoridad de primera clase"65.

Por otra parte, los conflictos internacionales que jalonaron la última década del siglo XIX volvieron a poner de manifiesto la carencia de un himno con el que el pueblo pudiera expresar sus sentimientos patrióticos. Y el pueblo encontró uno a su medida en la marcha de la zarzuela Cádiz, de Chueca y Valverde. La zarzuela había sido estrenada en el teatro Apolo de Madrid en noviembre de 1886, y desde el primer momento la marcha con la que los soldados españoles vencedores de las tropas napoleónicas desfilan al grito de iViva España! al final del primer acto despertó el entusiasmo del público. La marcha pasó inmediatamente al repertorio de las orquestas y bandas de música, y a sus sones desfilaron los ciudadanos en las manifestaciones patrióticas organizadas en marzo de 1893 por los sucesos de Melilla, a sus sones partieron las tropas españolas al
Rif en octubre de ese año y con sus acordes como música de fondo volvió a partir el ejército a los frentes de Cuba y Filipinas y regresó derrotado tras el desastre de 1898.

En su momento de apogeo, 1895-97, la marcha de Cádiz se convirtió en un auténtico himno nacional: "El pueblo se ha apoderado de este himno, las bandas militares lo tocan, los muchachos, cuando juegan a los soldados, lo cantan, y cuando nuestras tropas, como ha dos años, marchaban a Melilla, de igual modo que ahora parten para Cuba, la marcha de Cádiz evoca, tanto en los que se van como en los que se quedan, las energías belicosas de nuestra raza"66. El efecto patriótico que producía esta música en las tropas llegó a ser tal que el general Azcárraga, ministro de la Guerra, condecoró a Chueca en febrero de 1896 con la cruz blanca del mérito militar. Pocos días después de esta medida Mariano de Cavia, desde las páginas de El Imparcial, proponía un certamen para premiar la letra mejor adaptada a la música del iViva España! de Chueca y convertirlo en himno nacional ${ }^{67}$. La propuesta fue acogida con entusiasmo, aunque en las bases del certamen, publicadas el 5 de marzo, se rectificaba la denominación: "se ha convenido en preferir el nombre de Canto Patriótico al de Himno Nacional, que implica mayor solemnidad y tal vez no dejase a la inspiración del poeta toda la holgura apetecible en este caso".

La historia se volvió a repetir: a pesar de la avalancha de concursantes, más de doscientos, el jurado, presidido por Núñez de Arce y constituido además por los autores de Cádiz -Javier de Burgos, Chueca y Valverde-, los músicos Chapí y Bretón y los escritores Manuel del Palacio y Miguel Ramos Carrión, dejaron el concurso desierto. En su dictamen exponían que, aunque habia varias poesias "de verdadero mérito literario", sin embargo "la influencia tal vez de unas circunstancias sólo propicias para inspirar sentimientos belicosos, ha prestado a todas las poesías tonos tan marcadamente guerreros, que imprimirían al canto patriótico un carácter muy loable, sin duda, pero demasiado transitorio y ajeno al espíritu de este concurso"68. Efectivamente, Cavia había pedido letra para una canción "que el pueblo pudiera entonar en todas ocasiones, lo mismo en sus alegrías que en sus tristezas, en la guerra y en la paz...".

En este proceso no todo fueron opiniones favorables. El conocido crítico musical Antonio Peña y Goñi escribió un 
largo artículo lleno de ironía en el que citaba la marcha de Cádiz como "un pasodoble jacarandoso impuesto a un pueblo como himno nacional":

Hemos estado durante setenta y siete años, juna friolera! cantando como energúmenos la dichosa contradanza [el himno de Riego], a cuyos sones hemos derribado no sé cuántas Bastillas y soplado el fuego patriótico de cuatro generaciones.

Y todo ¿para qué? Para que al cabo de casi un siglo caigamos en la cuenta de que carecemos de himno nacional, de que gemimos y lloramos por un poema lírico, conciso y elocuente, que sintetice los fulminantes arrebatos de nuestra raza, los aerolíticos estallidos de nuestros nervios y la fermentación volcánica de nuestra sangre ${ }^{69}$.

Quizá si España no hubiera sido derrotada en Cuba y Filipinas la marcha de Cádiz habría continuado desempeñando las funciones de himno nacional. Pero la derrota provocó también el rechazo del pasodoble, al que se llegó a atribuir el clima de exaltación patriótica infundada que había acompañado a las tropas españolas. En el derrotista ambiente del noventa y ocho se acusó a la marcha de "farsa teatral": "no nació en el campo de batalla como La Marsellesa, sino en el escenario de un teatro por horas"; "al movido compás de su ritmo casi cancanesco pasaron y repasaron comparsas"; "no tiene la majestuosa grandeza de la Marsellesa ni la mística solemnidad de la Marcha Real, ni siquiera el bullicioso hervor patriótico del himno de Riego; [...] a patria chica, política menuda, guerras temerarias, aventuras suicidas, marcha de Cádiz a todo pasto"; "Oígase en la calle la Marcha Real granadera o la fusilera; oígase en la calle el himno ruso, el alemán o el inglés, tocados por las músicas militares, sin acompañamiento de chillidos histéricos de la muchedumbre [...], pero no repita un pueblo en la calle, cuando se halla en presencia de lo más grande que hay en la Patria, es decir, de sus hijos, que van a perder la vida por ella, la escena de la farsa teatral"70.

\section{La Marcha real ¿himno nacional?}

En los últimos años del siglo volvió a adquirir protagonismo en la vida política el debate, nunca cerrado, sobre el significado de la Marcha real. La crisis del 98 provoca también una crisis de la identidad nacional, que va acompañada por la creciente fuerza de los nacionalismos periféricos, especialmente el catalán. Fueron precisamente los sucesos acaecidos en el teatro Tívoli de Barcelona en julio de 1899 los que encendieron la polémica. En medio de un clima de insatisfacción en determinados círculos catalanes por los presupuestos presentados por el ministro de Hacienda Fernández Villaverde, tuvo lugar la visita a Barcelona de un grupo de unidades de la escuadra francesa. Durante el concierto de gala ofrecido a los oficiales franceses en el teatro Tívoli, un amplio sector del público, tras aplaudir La Marsellesa, hizo callar a la orquesta que iniciaba la Marcha real con gritos y silbidos. Los hechos tuvieron un eco inmediato en el Congreso de los Diputados, donde se debatió el tema en la sesión del 22 de julio. Lo que aquí nos interesa de ese debate es la utilización del término "himno nacional" -en lugar de Marcha real- por parte de Eduardo Dato, ministro de la Gobernación, inicio de una polémica que no se zanjaría hasta 1906. El País publicó un encendido artículo protestando por el empleo del término:

[...] ayer en el Congreso, cuando se habló de este incidente, los oradores monárquicos Ilamaban a la citada Marcha himno nacional.

[...] ¿Cuándo la Marcha Real ha hecho ese papel en España? ¿Le ha puesto letra algún poeta popular? ¿Se canta en las filas del pueblo? ¿Se asocia a los dolores y las alegrías de la nación?

Sirve cuando más para acompañar al viático o alguna procesión y para marcar el paso de ceremoniosas reuniones palaciegas.

Himnos nacionales en España son los ecos varoniles y salvajes del desperta ferro almogavar, las Jotas coreadas, el himno de Riego... pero ¡la Marcha Real!

A nadie puede ocurrírsele que una música cortesana, hecha para saludar a los reyes cuando van a comer, sea un himno de la nación ${ }^{71}$.

El debate vuelve al congreso en la sesión del día 24 de marzo de 1900, también en esta ocasión como consecuencia de un suceso ocurrido en Barcelona. Transcribimos el relato de la discusión entre el diputado republicano Muro y varios diputados conservadores -Dato, García Alix y Romero Robledo-, tal como aparece descrita en el diario carlista El Siglo Futuro:

[Sr. Muro] ¿Es delito el hecho de silbar unos compases de la Marcha Real? (Rumores). 
El Sr. Dato [...] califica la Marcha Real de himno nacional. (Grandes protestas en la minoría republicana).

El Sr. Muro: No es himno nacional. (Fuertes y prolongados rumores en toda la Cámara).

El señor Presidente (García Alix): Es el himno real y el himno nacional. (La mayoría asiente y los republicanos protestan). Rectifica otra vez el Sr. Muro. Que se me cite -añade- el artículo del Código en que se dice que es delito silbar la Marcha Real. (Nuevos rumores). Esto, por muy nacional que quiera el presidente de la Cámara que sea. (Más protestas). El Sr. García Alix: El presidente sólo quiere que se cumpla la legalidad.

El Sr. Muro: No es nacional porque no es popular. (La mayoría protesta otra vez; los republicanos dicen: -iMuy bien! y el incidente se hace un poco largo).

El Sr. Romero Robledo interviene en el debate. A mí me parece una cuestión de escasa importancia que a la Marcha Real se le llame himno nacional o no. Si la Marcha Real hubiera sido silbada, el ataque no habria sido a la monarquia, sino a la nación. [...] $]^{72}$.

En los meses y años siguientes la polémica continuó en la opinión pública. Desde dos medios tan dispares ideológicamente como La Correspondencia Militar y El Motín se proponía en agosto de 1901 la creación de un himno nacional, desde el primero argumentándose que la Marcha real era exclusivamente para los reyes y hacía falta un himno nacional "para todos los actos de la Patria, así civiles como militares"73, y desde el segundo aduciendo que a la Marcha real le faltaba un requisito para ser himno nacional, el asentimiento de la nación:

Las cuadrillas que operan en la política bajo la razón social Silvela-Dato o Sagasta-Moret son, sin duda, muy poderosas, pero no pueden aspirar a la dictadura filarmónica. Estas cosas son de aquellas que, como diría mi insigne amigo
Joaquín Costa, sólo pueden ordenarse ad referendum. No es posible que pase por himno de España una piececita que tiene el triste privilegio de encocorar a más del cincuenta por ciento de los españoles. El pueblo en masa no siente palpitar en esas notas el espíritu de la patria. En sus transportes de patriotismo, el francés entona los vibrantes compases de $L a$ Marsellesa, el inglés alterna el God save the queen con el Rule Britannia, el boer modula el canto semibíblico cuyos acordes le inspiran tan grandes heroísmos. Yo nunca he visto a un español que, henchido de patriótico entusiasmo, prorrumpiera en la consabida tonadilla: Chinda, chinda, tachinda, chinda, chinda.... ${ }^{74}$.

En 1906 la polémica, que seguia viva, volvió al Congreso, esta vez con motivo del debate sobre el proyecto de ley de jurisdicciones. Uno de los artículos propuestos en dicha ley, el $3 .{ }^{\circ}$, se refería a los delitos contra los signos, símbolos, banderas, escudos e "himno nacional". Ya antes del debate el diario El País afirmaba: "Se pena por este artículo los siseos, silbidos y otros signos de desagrado al himno nacional. Muy bien, Pero falta saber una cosa esencialísima: cuál es el himno nacional español"75. En la sesión del día 3 de marzo de 1906, en la que se discutió este artículo, el presidente del Congreso, Segismundo Moret, defendió frente a la argumentación del diputado republicano Zulueta que "la marcha real es el verdadero himno nacional". Finalmente, tras algunas modificaciones, el artículo $3 .^{\circ}$ pasaría a ser el 2. incluyendo la expresión "Himno nacional"76. Esto supuso el primer refrendo, aunque indirecto, de la consideración de la Marcha real como himno nacional español. El primer decreto oficial que establecia la Marcha granadera como Himno nacional español no llegaría hasta 1942, ya en época franquista ${ }^{77}$. Entretanto, el himno de Riego había vuelto a imponerse durante la Segunda República. Ambas marchas se habían convertido en símbolos de las dos Españas.

\section{NOTAS}

1 Cf. Fernández de Latorre Moreno, Ricardo: Historia de la música militar de España, Madrid, Ministerio de Defensa, 2000; Lolo, Begoña: "El himno", en Símbolos de España, Madrid, Centro de Estudios Políticos y
Constitucionales, 2000, pp. 375 y ss.; Ruiz Tarazona, Andrés: "Himno nacional español o Marcha real", en Diccionario de la Música Española e Hispanoamericana, vol. 6, Madrid, SGAE, 2000, p. 308; García Cuadrado, Antonio M.a: "El himno nacional de España", en Miguel Ángel Alegre
Recibido: 29 de octubre de 2010 Aceptado: 15 de enero de 2011 
(coord..) et al.: El himno como símbolo político, León, Universidad de León, 2008, pp. 91-111.

2 Revista Española, 17/10/1835; La Lucha de Clases, 11/03/1905.

3 Buch, Esteban: La novena de Beethoven. Historia política del himno europeo, Barcelona, El Acantilado, 2001, p. 10.

4 Distintos historiadores han subrayado la debilidad del estado liberal en España, ajeno a buena parte de los ciudadanos y con poca capacidad de penetración social y política. Destacamos, entre ellos: Fox, E. Inman: La invención de España: nacionalismo liberal e identidad nacional, Madrid, Cátedra, 1997; Fusi, Juan Pablo: España: la evolución de la identidad nacional, Madrid, Temas de Hoy, 2000; Álvarez Junco, José: Mater Dolorosa. La idea de España en el siglo XIX, Madrid, Taurus, 2001; Riquer i Permanyer, Borja de: Escolta, Espanya. La cuestión catalana en la época liberal Madrid, Marcial Pons, 2001, cap. I: "La débil nacionalización española del siglo XIX", pp. 35-58.

5 Calderón, Alfredo: "Un himno", El Motín, 24/08/1901.

6 "La Marcha Real tuvo durante casi dos siglos la consideración de himno nacional de España por reconocimiento popular, sin que fuese oficialmente declarado como tal en disposición legal alguna antes de 1938" (García Cuadrado, 91);

7 El Diccionario de la Lengua Española, en su vigésimo segunda edición (2001), ofrece las siguientes acepciones del término "Himno": 1. Composición poética en loor de los dioses 0 de los héroes. 2. Composición poética en alabanza de Dios, de la Virgen o de los santos. 3. Poesía cuyo objeto es exaltar a un gran hombre, celebrar una victoria u otro suceso memora- ble o expresar júbilo o entusiasmo. 4. Composición musical dirigida a cualquiera de estos fines. 5. Composición musical emblemática de una colectividad, que la identifica y que une entre sí a quienes la interpretan.

8 No abordamos aquí el origen ni la significación posterior del Himno de Riego, tema tratado extensamente por Enrique Téllez Cenzano en la tesis doctoral que está finalizando en el momento de elaboración de este artículo (octubre de 2010).

9 El Constitucional, 10/05/1820.

10 Diario de Madrid, 21/04/1820.

11 El Constitucional, 25/04/1820.

12 Álvarez Junco, José: Mater Dolorosa..., p. 33.

13 Colección de los Decretos y órdenes generales expedidos por las Cortes desde $1 .{ }^{\circ}$ de marzo hasta 30 de junio de 1822. Tomo IX, Madrid, Imprenta Nacional, 1822, p. 57.

14 Diario de las Sesiones de las Cortes. Legislatura de 1822. Tomo I, Madrid, Imprenta de J.A. García, 1872, p. 693.

15 La única modificación que se introdujo respecto al texto propuesto originalmente fue la sustitución de la expresión "ejército libertador" por "ejército de San Fernando" (Diario de las Sesiones de las Cortes: sesión de 7 de abril de 1822).

16 No se conoce el origen de estas marchas. Durante el siglo XIX se difundió un relato según el cual Federico II de Prusia habría regalado la Marcha granadera a Carlos III a través de su ministro de Estado el conde de Aranda, pero esta leyenda no ha podido ser comprobada hasta el momento.

17 Cf. Nagore Ferrer, Maria: "Carlismo y música", en Imágenes. El carlismo en las artes, Pamplona, Gobierno de Navarra, 2010, pp. 245-280.
18 Lafuente, Modesto: Historia General de España, parte tercera: Edad Moderna, tomo XXVII, Madrid, 1865, pp. 407-408.

19 La Revista Española, 9/08/1833.

20 Eco del Comercio, 22/06/1834.

21 La Revista Española, 27/11/1834.

22 Citado por La Revista Española, 28/11/1834.

23 Es conocido el relato de la proclamación de Luis Felipe de Orléans como rey de Francia tras la revolución de 1830: el nuevo rey sale al balcón rodeado por su familia y flanqueado por el general Lafayette y varios diputados populares; la multitud, enardecida, grita, agita los sombreros y la Marsellesa suena con fuerza uniéndose Luis Felipe al canto, en coro con los ciudadanos. A pesar de ello, la monarquía de julio prefirió como himno La Parisienne y desde 1832 La Française. La Marsellesa terminaría siendo cantada por los partidarios de la caída del monarca, y tras muchas vicisitudes no volvería a ser proclamada himno nacional francés hasta 1878.

24 Decretos de la Reina Nuestra Señora doña Isabel II, dados en su Real Nombre por su Augusta Madre la Reina Gobernadora, y reales órdenes, resoluciones y reglamentos generales expedidos por las secretarías de despacho universal desde $1 .{ }^{\circ}$ de enero hasta fin de diciembre de 1835 por Don Josef María de Nieva, tomo vigésimo, Madrid, Imprenta Real, 1836, pp. 91-92.

25 Precisamente desde marzo de 1835 el curso de la guerra había dado un vuelco, sucediéndose las victorias de ejército carlista hasta finales de junio de ese año.

26 Revista Española, 21/10/1835.

27 Gómez, Alejandro: Los sucesos de La Granja en 1836. Apuntes para la his- 
toria, Madrid, Imprenta de Manuel de Rojas, 1864, pp. 12-13.

28 Cf. Morales Moya, Antonio: "Isabel II en el régimen político liberal", en Pérez Garzón, Juan Sisinio (ed.): Isabel II: Los espejos de la reina, Madrid, Marcial Pons, 2004, pp. 61-74.

29 Riquer i Permanyer, Borja de: Escolta, Espanya..., pp. 35-58.

30 El Heraldo, 5/05/1843.

31 El Pensamiento de la Nación, 3/07/1844.

32 "El Ferro-carril de Aranjuez. Su inauguración en 9 de febrero de 1851", La España, 11/02/1851. Aunque el artículo no lleva firma, el periódico Eco Literario de Europa desvela: "Aunque el artículo apareció sin la firma de su autor, nadie ignora que es de D. Antonio María Rubio, secretario de S. M. la Reina madre, cuyas producciones son siempre leídas con gusto, y es sensible que sean tan escasas".

33 Citado por El Clamor Público, 12/11/1851.

34 Colección Legislativa de España (continuación de la colección de Decretos). Tercer cuatrimestre de 1853. Tomo LX, Madrid, Imprenta Nacional, 1854, pp. 51-52.

35 El Heraldo, 13/09/1853.

36 La lberia, 1/11/1854.

37 Se trata de la fuente conocida como del Geni català, uno de los monumentos más destacados de la Barcelona del siglo XIX, erigida en honor del capitán general de Cataluña Marqués de Campo Sagrado. El monumento se había comenzado en 1851, proyectado por el arquitecto Francesc Daniel Molina.

38 La lberia, 6/06/1856.

39 La España, 17/04/1855.

40 Citado por La Esperanza, 21/04/1855.

41 "Cuaderno de bitácora del Capitán Bombarda. Singladura LV", La Iberia, 13/03/1859.
42 En 1862 el editor Casimiro Martín publica cuatro cuadernos para piano titulados Cantos y Marchas nacionales del universo que incluye los himnos de México, Estados Unidos, Brasil, Chile, Perú, Buenos Aires, Italia, Cerdeña, Inglaterra, Bélgica, Egipto, Dinamarca, Francia, Rusia, Arabia, Portugal, Turquia, Austria, Prusia, Baviera, Polonia, Bohemia y Hungría. Es significativo que incluya además las dos Marchas reales españolas.

43 La Discusión, 3/11/1859.

44 La España, 4/11/1859.

45 La Discusión, 1/04/1860. Ese periódico opinaba que "es elegante y marcial, y en nuestro entender Ilena todas las condiciones de un bello himno nacional". El himno fue publicado en cinco ediciones: para piano y canto, para banda militar, para orquesta teatral y voces, para una o dos voces (flautas, cornetines, etc.) sin acompañamiento y para canto y guitarra.

46 La Época, 14/04/1860.

47 Desde La lberia se defiende la validez del himno de Riego como himno nacional, mientras que medios contrarios ideológicamente como La Época - La Esperanza lo critican.

48 Cf. La España, 12/03/1864.

49 La lberia, 13/03/1864.

50 Riquer, p. 53.

51 El Lloyd Español, 10/02/1864.

52 Este himno se estrenó, bajo la dirección de Arrieta, el 5 de noviembre de 1868 en el acto organizado por la fusión entre la antigua Tertulia Progresista y el Círculo de la Unión. Olózaga afirmó, en dicho acto, que el himno "podía considerarse como el verdadero himno nacional de la España regenerada" (La Correspondencia de España, 6/11/1868).

53 La Discusión, 8/12/1868.

54 La marcha fue editada por Casimiro Martín con el siguiente encabe- zamiento: "Nueva Marcha Nacional compuesta expresamente, según la orden del Excmo. Señor Ministro de la guerra, para ser ejecutada por todas las Bandas de música de la guarnición el día de la apertura de las Cortes Constituyentes, por José Sqadrani, Músico Mayor del Segundo Regimiento de Ingenieros. (Esta Marcha es la que, de orden superior, ha de sustituir a la Marcha Real en todos los actos en que aquélla se tocaba)".

55 Gil Blas, 27/06/1869.

56 La Época, 22/10/1870.

57 Gaceta de Madrid, 19/12/1870.

58 La Época, 2/01/1870.

59 El Imparcial, 4/01/1871.

60 Carta desde Pamplona, 25 de febrero de 1873, publicada en La Esperanza, 1/03/1873.

61 En relación con este himno, leemos en la prensa: "Ha sido tan considerable la venta del nuevo himno de la república española publicado por el editor de música señor Romero, que ha sido preciso grabar dobles láminas para que los estampadores puedan dar abasto a los pedidos" (La Correspondencia de España 19/02/1873)

62 Esta sociedad, cuya vida se extiende desde 1847 hasta alrededor de 1933, tuvo un período de esplendor durante el Sexenio Democrático. Su ideología y actividades han sido estudiadas por Leticia Sánchez de Andrés: Música para un ideal: pensamiento y actividad musical del krausismo e institucionismo españoles (1854-1936)، Madrid, Sociedad Española de Musicología, 2009, pp. 557-574.

63 Cf. Andrés Corzuelo: "La marcha real", en El Globo, 18/05/1884; La Iberia, 9/10/1892; El País, 15/10/1892 y 25/10/1892.

64 El Correo Militar, 30/11/1888. 
65 La Época, 27/08/1887.

66 Matamoros: "Crónicas madrileñas. El himno nacional", La Época, 17/02/1896.

67 Mariano de Cavia: "¡Viva España!" Himno nacional. Un certamen", El Imparcial, 21/02/1896.

68 El Imparcial, 31/03/1896.

69 Antonio Peña y Goñi: "Crónicas madrileñas. ¡Viva España!", La Época, 29/02/1896.

70 Luigi, "La marcha de Cádiz", Vida Nueva, 12/06/1898; N: "Entresijos", El Globo, 19/09/1898.
71 "La Marcha Real bailable", El País, 26/07/1899.

72 El Siglo Futuro, 26/03/1900.

73 Daniel Collado: "Un himno nacional", La Correspondencia Militar, 21/08/1901.

74 Alfredo Calderón: "Un himno", El Motín, 24/08/1901.

75 "El himno nacional", El País, 28/02/1906.

76 "Art. 2. Los que de palabra, por escrito, por medio de la imprenta, grabado, estampas, alegorías, caricaturas, signos, gritos o alusiones ultrajaren a la Nación o su bandera, Himno nacional u otro emblema de su representación, serán castigados con la pena de prisión correccional. En la misma pena incurrirán los que comentan iguales delitos contra las regiones, provincias, ciudades y pueblos de España y sus banderas o escudos."

77 Decreto de 17 de julio de 1942 (B.O.E. del 21 de julio). Este decreto había sido precedido por otro, dictado el 27 de febrero de 1937 (B.O.E. del 28 de febrero), que establecía la Marcha Granadera como Himno nacional de España. 